1 Universidade Federal de São Paulo (Unifesp), Departamento de Gestão e Cuidados em Saúde Santos (SP), Brasil.

fernanda.frutuoso@unifesp.br

2 Universidade Federal de São Paulo (Unifesp), Departamento de Gestão e Cuidados em Saúde Santos (SP), Brasil. virginiaj@uol.com.br

3 Universidade Federal de São Paulo (Unifesp), Departamento de Gestão e Cuidados em Saúde Santos (SP), Brasil. angeruma@uol.com.br

\section{A experiência de formação (em) comum de nutricionistas na Unifesp, campus Baixada Santista}

\author{
The training experience (in) common of nutritionists at Unifesp, \\ Baixada Santista campus
}

Maria Fernanda Petroli Frutuoso', Virginia Junqueira ${ }^{\mathbf{2}}$, Ângela Aparecida Capozzolo ${ }^{\mathbf{3}}$

RESUMO Para discutir a experiência de formação em comum do eixo Trabalho em Saúde, da Universidade Federal de São Paulo, delineou-se estudo qualitativo conduzido por meio de grupo focal, com concluintes do curso de nutrição. Evidenciaram-se tensões não somente entre o específico e o comum nas práticas profissionais, mas na concepção de cuidado e clínica. Efeitos importantes na formação foram relatados, na medida em que as atividades do eixo fizeram um convite à criação e invenção de outros modos de cuidar em nutrição, a partir da contaminação/combinação de áreas profissionais, afastando-se de práticas normativas, insuficientes para dar conta da complexidade da alimentação e nutrição, na atualidade.

PALAVRAS-CHAVE Ensino. Nutricionistas. Sistema Único de Saúde. Integralidade em saúde.

ABSTRACT To discuss the training experience in common of the Health Work axis, of the Federal University of São Paulo, a qualitative study was outlined conducted through a focus group, with graduates of the nutrition course. Tensions were evident not only between the specific and the common in professional practices, but in the conception of clinical and care. Important effects on training were reported, as the activities of the axis invited the creation and invention of other modes of care practices in nutrition, from contamination/combination of professional areas, moving away from normative practices, insufficient to handle the complexity of food and nutrition, nowadays.

KEYWORDS Teaching. Nutritionists. Unified Health System. Integrality in health. 


\section{Introdução}

\begin{abstract}
O chá pra curar esta azia
Um bom chá pra curar esta azia

Todas as ciências de baixa tecnologia

Todas as cores escondidas nas nuvens da

rotina

Pra gente ver... por entre prédios e nós...
\end{abstract}

(Yuka, 1999)

O campo da alimentação e nutrição, em suas dimensões científica, profissional e política, surge, no Brasil, no final da década de 1930 (VASCONCELOS; BATISTA-FILHO, 2011). A prática dos profissionais da nutrição tem sua origem ligada à crescente especialização da prática médica. Inicialmente, atuam como auxiliares do trabalho médico (em uma relação de subordinação), responsáveis pela dieta de pacientes internados nos hospitais. A ênfase na dimensão biológica e nos aspectos clínico-fisiológicos associados ao consumo dos nutrientes dá origem ao campo da nutrição clínica. Esse campo foi se constituindo com uma progressiva fragmentação e especialização (em subáreas de atuação, por grupos etários, de patologias e outros) focada em ações individuais, curativas e hospitalares (DEMETRIO, 2011).

Outra perspectiva reunia aqueles cuja atenção voltava-se para os aspectos socioeconômicos e populacionais relacionados à produção, à distribuição e ao consumo de alimentos. Inicialmente, estudos desse campo caracterizaram a fome e as carências alimentares e nutricionais do País, e subsidiaram programas de assistência alimentar desenvolvidos pelo Estado, direcionados a grupos populacionais prioritários.

Essas perspectivas influenciaram a organização do ensino em nutrição, dividido em grandes áreas, resultando em objetos bem particulares de estudo e trabalho. Vale destacar, no entanto, que a formação concentrou-se fundamentalmente no preparo dos profissionais para o trabalho em instituições hospitalares, na área clínica e de alimentação institucional (VASCONCELOS; CALADO, 2011). Assim como nas demais áreas do campo da saúde, a conformação histórica das práticas profissionais resultou no fortalecimento da especialização, da fragmentação dos conhecimentos e práticas, na tecnificação e no biologicismo (AROUCA, 2003; MERHY ET AL., 2010).

A complexidade das práticas alimentares e sua interface com o processo de saúde-adoecimento-cuidado envolvem dimensões sociais, subjetivas, culturais e simbólicas, que tendem a ser pouco consideradas pelos profissionais, resultando em práticas pouco efetivas. As condutas hegemônicas baseiam-se em prescrições dietéticas normativas e culpabilizadoras, com enfoques predominantemente biológicos e, muitas vezes, reduzidos à orientação de mudança de hábitos alimentares, definidas a partir da relação da dieta com o risco de adoecimento e morte (BOSI; PRADO, 2011; SANTOS, 2012).

A partir da década de 1970, no Brasil, avolumam-se as investigações que apontam a distribuição da renda, da terra e as condições sociais como principais determinantes da fome e dos problemas nutricionais, e ampliam-se as críticas ao distanciamento entre os modelos de formação e as necessidades de atenção da população. Movimentos críticos destacam a importância da garantia do direito humano à alimentação, bem como de um conjunto de condições e serviços necessários à prevenção, promoção, manutenção e recuperação da saúde (VASCONCELOS; BATISTAFILHO, 2011).

Com o movimento da Reforma Sanitária e a instituição do Sistema Único de Saúde (SUS), avança o debate sobre a necessidade de mudanças na graduação dos profissionais de saúde, incluindo os de nutrição. Ganha destaque a importância de ampliar a compreensão das diversas dimensões envolvidas no processo saúde-doença e do trabalho integrado entre as diversas áreas profissionais para intervir nos problemas de saúde da população. As novas diretrizes curriculares nacionais, homologadas a partir de 2001, 
propõem competências comuns para todas as profissões, ênfase na diversificação de cenários de aprendizagem e na inserção no SUS (BRASIL, 2001; SOARES; AGUIAR, 2010; FEUERWERKER; CAPOZZOLO, 2013).

Nesse contexto de mudanças, se insere o curso de graduação em nutrição da Universidade Federal de São Paulo, campus Baixada Santista (Unifesp-BS). Implantado em 2006, em conjunto com outros cursos da área de saúde (educação física, fisioterapia, psicologia e terapia ocupacional), tem um desenho curricular estruturado em quatro eixos, que rompem com a estrutura disciplinar tradicional e com a formação isolada de uma única profissão. Um dos eixos - 'Aproximação à prática da nutrição' - é denominado eixo específico e está direcionado somente aos estudantes de nutrição. Os outros três eixos - 'Trabalho em Saúde', 'O ser humano e sua inserção social' e 'O ser humano e sua dimensão biológica' - são comuns, mesclando alunos dos vários cursos (UNIFESP, 2006).

Embora se reconheça a importância de todos os eixos para a formação, neste artigo optou-se por discutir algumas questões que têm emergido do eixo comum 'Trabalho em Saúde' (TS), por ser um diferencial desta proposta de formação.

As atividades do eixo TS, organizadas em módulos semestrais, percorrem os três primeiros anos de graduação e pautam-se na aprendizagem baseada na experiência. Para Bondía (2002, P. 21), a "experiência é o que nos passa, o que nos acontece, o que nos toca". No percurso da formação, são utilizadas diferentes estratégias, que procuram expor os estudantes ao encontro com usuários e equipes da rede de serviços e com as condições de vida e de saúde da população.

Nesse eixo, foi alocada parte dos conteúdos do campo da saúde coletiva (políticas públicas, sistema de saúde; organização do processo de trabalho e da rede de serviços; conceito de saúde; trabalho em equipe; e cuidado integral, entre outros), na perspectiva de compor com outros saberes e práticas para contribuir na constituição de certo 'modo de pensar e agir' dos futuros profissionais. Neste sentido, docentes da área de saúde coletiva e das distintas áreas profissionais integram o eixo e se mesclam para o apoio e a supervisão das atividades de ensino, que buscam problematizar as diversas dimensões envolvidas no processo saúde-doença e favorecer a construção de práticas integradas implicadas com a produção de cuidado e da vida.

A diretriz que orientou a estruturação desse eixo foi a busca do comum às várias áreas profissionais. Uma dimensão desse comum diz respeito ao que é importante na clínica de qualquer profissional de saúde, como a escuta, a capacidade de estabelecer relações de confiança, vínculo, diálogo, ética, responsabilização. Outra dimensão diz respeito ao que se realiza no encontro das diferenças das áreas profissionais, na produção de estratégias compartilhadas de intervenção, na exploração do 'entre' as áreas disciplinares. Essas dimensões compõem o que temos denominado clínica 'comum' às várias áreas profissionais (CAPOZZOLO ET AL., 2013).

Essas perspectivas articulam conteúdos e estratégias que atravessam os diferentes módulos e buscam fornecer recursos aos estudantes para lidarem com o momento do encontro clínico e para estabelecerem relações. As vivências, processadas em espaços de supervisão com os docentes, permitem explorar diversas dimensões envolvidas no trabalho em saúde e na produção do cuidado, para além da utilização de técnicas, protocolos e procedimentos específicos de cada profissão. Optou-se por inserir as atividades de ensino nas áreas de maior vulnerabilidade social do município de Santos (SP).

No primeiro e no segundo semestre da graduação, os estudantes realizam atividades de reconhecimento de diferentes territórios do município onde se localiza o campus, que possibilitam perceber os diversos modos de vida da população e suas implicações 
para o processo saúde-doença-cuidado. Abordam-se, ainda, as políticas e a organização dos serviços de saúde. Nos semestres seguintes, a ênfase está no trabalho com histórias singulares de vida e de saúde. No terceiro semestre de graduação, duplas de estudantes de cursos diferentes visitam, durante o semestre, uma pessoa ou família, em suas residências, com o objetivo de construírem narrativas de suas histórias de vida e de saúde. No quarto semestre, equipes mistas de estudantes elaboram e implementam ações de promoção de saúde com grupos populacionais. No quinto e no sexto semestre, os estudantes se organizam em equipes mistas para realizarem projetos terapêuticos de cuidado.

Pesquisa realizada com a primeira turma de formandos apontou para a produção de experiências marcantes desse eixo, na formação. Tendo como perspectiva a formação de nutricionistas, este artigo tem como objetivo apresentar e discutir as questões que emergem dessa experiência de formação.

\section{Material e métodos}

Esta pesquisa, de natureza qualitativa, foi conduzida pelo Laboratório de Estudos e Pesquisas sobre Formação e Trabalho em Saúde (Lepets), no período de 2009 a 2011, e foi aprovada pelo Comitê de Ética da Universidade (Parecer 1.528/09).

O projeto 'Formação para o trabalho em saúde: a experiência em implantação nos cursos de graduação - Educação Física, Fisioterapia, Nutrição, Psicologia e Terapia Ocupacional da Universidade Federal de São Paulo - Campus Baixada Santista', mediante o processo no Conselho Nacional de Desenvolvimento Científico e Tecnológico (CNPq) no 479031/2008-8, almejou sistematizar, analisar e aprimorar a proposta de formação profissional desenvolvida a partir do eixo TS, estabelecendo estratégias para o acompanhamento, a avaliação e a sustentabilidade desta experiência.

Para saber se tal aposta de formação surtia os efeitos desejados, foram realizados grupos focais, separadamente, com dez estudantes sorteados, de cada um dos cursos, concluintes da primeira turma, bem como um grupo focal com dois docentes de cada curso. Os encontros foram conduzidos por um coordenador, segundo procedimentos pré-estabelecidos, tendo como pauta o relato de experiências marcantes, que envolveram a aprendizagem com alunos de outras áreas, docentes, equipes de saúde e população. Também foram realizadas entrevistas individuais semiestruturadas com os coordenadores dos cursos e com oito profissionais (chefia e enfermeiros) das equipes onde eram desenvolvidas atividades do eixo havia mais de um ano.

Cada material foi analisado, separadamente, por três pesquisadores, de diferentes áreas de formação. Elaborou-se uma matriz de sistematização dos temas inicialmente identificados, dos diferentes posicionamentos com os trechos de discursos mais significativos, bem como com as impressões e problematizações que emergiram durante a leitura. Em seguida, o material foi discutido pelo conjunto de 20 pesquisadores que compõem o Lepets, para a agregação dos materiais em grandes núcleos temáticos. Posteriormente, foram apresentadas, em seminários, as análises preliminares com os sujeitos da pesquisa e com interlocutores externos. O material desses encontros integrou a análise e contribuiu na constituição de uma síntese final' ${ }^{1}$.

Neste artigo, houve interesse em destacar os achados desta experiência que se relacionam à formação na área de nutrição, analisando efeitos, tensões e reflexões que emergiram dos relatos do grupo focal, composto por oito estudantes concluintes da primeira turma deste curso, entre os dez sorteados para participar. As questões problematizadoras do encontro envolveram:
1 O conjunto de resultados e reflexões desta pesquisa foi publicado no livro 'Clínica comum: itinerários de uma formação em Saúde', organizado por Capozzolo et al., 2013. 
1. A experiência dos estudantes na atuação interprofissional com as equipes de saúde, pessoas/famílias/grupos e com alunos das outras áreas profissionais; 2. Compreensão das atividades de ensino-aprendizagem propostas pelo eixo TS; e 3. Possíveis efeitos e impactos das atividades de ensino-aprendizagem do eixo, na formação do estudante.

A literatura aponta como vantagem do grupo focal a interação entre os participantes a respeito das questões colocadas, favorecendo o intercâmbio de percepções e argumentos, e de opiniões formadas com base tanto no consenso como nas diferenças. Entre as desvantagens, encontram-se as dificuldades de criar interação e comunicação da forma mais espontânea possível, em um processo de discussão distante de apenas responder individualmente às questões propostas a partir do papel ativo do moderador como facilitador deste processo (GATTI, 2005). Neste estudo, e escolha do grupo focal se justifica pelo interesse em que os estudantes falassem o que já pensavam sobre a experiência de formação no eixo, e também aquilo que ainda não haviam formulado, mas que poderia ser pensado a partir da discussão em grupo. Assim, as posições foram sendo construídas no debate, tendo como resultado um produto coletivo, sem a necessidade de ser harmonioso ou homogêneo. A grupalidade propiciada pela técnica de grupo focal apresentou, ainda, "uma oportuna sintonia com as práticas que o TS colocava em exercício na formação" (CASETTO ET AL., 2013, P. 98).

O material transcrito do grupo focal da nutrição foi tratado pela análise temática, na qual os valores de referência e os modelos de comportamento presentes no discurso são caracterizados pela presença de determinados temas (MINAYO, 2010). Foram identificadas unidades de contexto (ideia central) e, em cada uma delas, unidades de registro (relatos), aglutinadas nos seguintes itens: 1) formação e clínica comum; 2) entre o específico e o comum: o que as tensões revelam?

\section{Resultados e discussão}

\section{Formação e clínica comum}

Os comentários que os alunos da nutrição apresentaram sobre o eixo TS apontam que os módulos permitem experimentar um tipo de organização de trabalho em equipe diferente da que habitualmente ocorre em sala de aula:

[...] a gente fazia trabalhos juntos, mas era mais separado. Acabava que sempre o aluno de nutrição pesquisava só a parte de nutrição, o aluno de TO só de TO, e juntava [...], mas no eixo de TS já não, tentava englobar uma visão diferente de como aplicar [...] tinha que relacionar todas as profissões, então, acho que foi essencial isso. (E2).

Os diferentes arranjos e estratégias dos módulos propõem a realização de ações conjuntas, em campo: "[...] no TS que a gente teve mais uma aproximação prática. A gente ia para os locais, visitava, discutia os casos, fazia tudo isso junto" (E1).

Os estudantes apontam que, nas reiteradas vivências, têm a oportunidade de ampliar o olhar sobre cada profissão, de conhecer as diferenças, as possibilidades e os limites de cada área:

Um aspecto que eu acho interessante, é que pelo menos um pouco dos cinco cursos que existem, a gente sabe descrever, $[. .$.$] as atribuições de cada$ um, na sua profissão. (E2).

Para além de conhecer o que cada profissão faz, as atividades de ensino do eixo permitem vivenciar 'algo' a mais, “[...] a gente precisava achar uma maneira de intercalar as duas coisas, para um bem maior" (E5). Os alunos reconhecem que, nas experiências conjuntas com tarefas de cuidado de complexidade crescente, aprendem a "[...] saber respeitar o limite de cada profissão, mas também saber interagir" (E6). 
Nunes (2002) enfatiza a importância da integração de saberes e práticas, a partir de problemas a serem enfrentados, em um processo construído entre a ciência, o mundo vivido e a vida prática, para além da simples justaposição ou complementaridade entre os elementos disciplinares. No percurso de formação do eixo, as vivências de cuidado vão exigindo diferentes recursos e combinações de saberes e práticas, que possibilitam aos estudantes incorporar em sua prática profissional o que reconhecem como sendo repertório de outros cursos e experimentar a potência de ações que inventam em comum.

As experiências, desde o início da formação, nos territórios de maior vulnerabilidade social, permitem o encontro com as pessoas que lá vivem, com suas condições e histórias de vida:

Experiência significativa foi conhecer a realidade de outras pessoas que eu nunca imaginei, [...] é totalmente diferente da que eu vivo em São Paulo [...] foi bem contrastante. (E1).

Estes encontros contribuem para que os estudantes percebam que suas intervenções têm que considerar as situações singulares de vida: "[...] que a pessoa está inserida numa sociedade, e até que ponto o ambiente está interferindo na relação saúde/doença” (E4).

As estratégias de ensino direcionam para reiteradas experiências de escuta e de deslocamentos em direção ao 'outro':

$\mathrm{NaTS}$, a gente realmente aprende a se interessar pelo outro, [...] se interessar de verdade, escutar aquilo que eles estão falando, dar importância ao que eles estão trazendo. (E2).

Possibilitam o reconhecimento de diferentes perspectivas e da necessidade de estabelecer diálogo, como explicita o trecho a seguir:

[...] ela não querer aquilo, [...] ela não aceitava aquela proposta, às vezes a gente até ia com coisas legais para passar, até tentava passar, aí entrava a ajuda de outros companheiros, de outros cursos, que às vezes nos ajudavam nisso também, de como abordar aquela pessoa. (E3).

No desafio de fazer intervenções em comum, os estudantes vão exercitando o estabelecimento de laços de confiança, de vínculos, e incorporando certo modo de atuar, de fazer clínica, como segue: "A gente acostumou a conversar, escutar, considerar vários aspectos" (E7). No momento do estágio, percebem com mais clareza a diferença da formação que receberam:

Eu fiquei escutando um açougueiro, fiquei mais de 40 minutos, [...] então, eu vi a diferença [...] a estagiária de outra universidade saiu, me deixou lá [...]. (E3).

Todos os estudantes referiram vivências significativas, nas quais reconheceram que produziram diferenças com as ações que realizaram, e que afetaram e foram afetados durante os encontros:

O impacto é muito grande, que você causa na pessoa e ela causa em você. (E6).

[...] sempre, numa relação que você vai deixar alguma coisa e vai receber também. (E5).

É realmente uma troca: a gente não está lá só para passar o nosso conhecimento, a gente também aprende muito. (E8).

Como referem Henz et al. (2013), as estratégias de ensino possibilitam:

[...] uma escuta descentrada, que tira do centro o poder da palavra profissional e pode levar à porosidade dos vários signos silenciosos produzidos nos encontros. Esse descentramento da escuta pode abrir espaços sutis de implicação ética e pensamento clínico - exercícios para o trabalho em equipe, com 
as decomposições e composições que podem ocorrer a cada caso. (HENZ ET AL., 2013, P. 164).

Os depoimentos demonstram que os encontros interprofissionais para produção de cuidado possibilitam uma contaminação e/ou combinação de saberes/práticas, permitindo a criação e invenção dentro da sua própria área profissional, como explicita a fala abaixo:

A gente fez a linha da vida com ela, um recurso de psicologia. Como ela era analfabeta, a gente relatou, em figuras, em recortes, a história de vida dela e, quando ela abria e via o livro, ela chorava. Nossa, nunca tinha pensado nisso! Então, essa troca de recursos de outros cursos, que a gente não tem muito acesso, foi muito emocionante, porque, se eu tivesse, talvez, a formação tradicional de nutrição, eu nunca pensaria em algo assim, algo tão simples, que trouxe tanta felicidade para alguém. Então, acho que abre muito o nosso olhar. (E5).

Os trechos a seguir exemplificam algumas atividades marcantes para os alunos da nutrição, tanto em grupo como individuais, realizadas em conjunto com outros estudantes, nos diferentes módulos:

Foi uma apresentação dos adolescentes do Centro de Juventude. A primeira vez que eles apresentaram, nós viramos plateia. Então, foi muito lindo, [...] ao mesmo tempo, a gente montou uma peça de teatro da nossa vivência na faculdade. Então, foi uma troca muito gostosa. (E1).

[...] o paciente já tinha tido vários $A V C s$, e ele nem andava. E quando saímos de lá, ele estava andando, abriu a porta, fechou, foi muito gratificante. (E3).

Eu lembro que a gente fez um grupo de idosos e, no último dia, a gente fez um bailinho para se despedir. Teve comes e bebes e tudo, e, no último dia, eles entregaram uma mensagem pra gente. (E4)
Sucintamente, os estudantes ilustram que as experiências que vivenciam nos diferentes módulos do eixo deixam marcas, e que as estratégias de ensino favorecem a escuta das histórias de vida, para a construção de ações que compõem um modo de fazer.

Pode-se dizer que, nos encontros, no exercício entre as diferentes profissões, vai ocorrendo a aprendizagem de certo modo de compreender e intervir nos problemas de saúde, e essa experiência de formação se aproxima da discussão de Abrahão e Merhy (2014), sobre a disposição para experimentar o ato do trabalho em saúde com abertura para sensações e afetos, cujo ponto de partida é o próprio encontro, com diferentes possibilidades, produzindo-se no cuidado.

O eixo possibilita o diálogo entre as práticas de cada área e a constituição de uma clínica 'comum', na medida em que, conduzidos pelo encontro, docentes e estudantes experimentam certos 'conceitos-tecnologias', que resultam em formas de pensar, sentir e fazer comuns, pertencentes e constitutivas de todas as profissões, inclusive a de nutricionista (HENZ ET AL., 2013).

\section{Entre o específico e o comum: o que as tensões revelam?}

Se, por um lado, os estudantes referem a possibilidade de uma combinação de elementos e estratégias de cuidado de cada área profissional, e valorizam os novos conhecimentos e práticas que proporcionam, por outro, explicitam tensões que a proposta de formação do eixo traz, como se vê no depoimento a seguir:

Porque a nossa insegurança era justamente tentar aliar algo de nutrição, porque a gente absorveu tanto a questão de escutar a pessoa, e a gente ficava inseguro: 'Será que eu vou conseguir ser uma nutricionista assim, algo bem específico? Como que vai ser?'. (E5).

Ainda que os estudantes reconheçam a importância do trabalho comum entre 
as várias áreas profissionais, verbalizam o receio de que a profissão que escolheram se dilua no campo do trabalho em saúde, perdendo sua singularidade. As tensões aparecem quando os alunos relatam a insegurança diante de não saber agregar a especificidade do curso à prática do eixo TS e apontam que 'escutar a pessoa' parece não pertencer ao escopo de ações do profissional de nutrição ou significar um 'algo a mais', que toma sentido somente se não confrontar as ações específicas da área profissional.

Eles ainda explicitam que ficam temerosos diante da possibilidade de realizar ações mais 'comuns' e perderem a identidade profissional, ao não executarem atividades que entendem como sendo mais 'técnicas' e singulares da nutrição, como apresenta o trecho a seguir:

Tem algumas áreas que necessitam de situações um pouco mais técnicas [...] tiveram alunos que falaram: 'Nossa, mas você precisa de uma balança, parece carne em açougue'! É a mesma coisa que você pedir para um psicólogo não conversar com o seu paciente, porque, infelizmente, nutrição, ou felizmente, a gente tem algumas coisas que tem que fazer como nutricionista, por mais que a gente entenda o ser humano, a integralidade. Para ter um diagnóstico de nutrição, a gente precisa usar alguns instrumentos, que são básicos, e que, no momento, talvez não era, mas foi meio que banalizada a situação. (E5).

Assim, expressam a concepção que ser nutricionista implica a aplicação de alguma técnica do repertório profissional, aqui exemplificada pelo uso da balança (ainda que a utilização deste instrumento não seja somente atribuição de nutricionistas). Também é possível perceber que os alunos criam a expectativa de que estar no eixo é uma oportunidade de aplicação prática do aprendizado obtido nos espaços intramuros, como segue: "Às vezes, a gente estudava algumas coisas, e a gente queria aplicar aquilo" (E3). Neste sentido, o foco das atividades do eixo
TS não é apenas o de possibilitar a 'aplicação prática' da teoria.

As vivências nos diferentes módulos do eixo produzem tensões também quando os estudantes percebem que, após o diagnóstico, precisam negociar e pensar na construção processual de um cuidado que faça sentido para a pessoa que está sendo atendida. Parece ser significativa a dificuldade de negociar com aquilo que o usuário está pedindo, na medida em que não se trata de desvalorizar o uso de instrumentos, mas de perceber o que a situação pede.

Sobre esse modelo de formação, pode-se apontar que se trata de abrir caminhos para o aluno aprender com a experiência, provocando um constante movimento de questionamento e dúvida, sem que um caminho seja cristalizado como único e/ou correto, e, a partir da perspectiva de que um profissional deve dispor de recursos para descobrir possibilidades diante dos desafios técnicos, éticos e políticos do cotidiano do trabalho em saúde.

O eixo TS aposta em uma formação que valoriza os espaços micropolíticos do cuidado, pois o trabalho em saúde lida com um objeto especial, que não é plenamente estruturado, o que coloca, inevitavelmente, as práticas profissionais prescritivas e normativas em análise. Não se trata de negar a utilização de técnicas inerentes à profissão (como o uso da balança), mas de promover uma prática reflexiva do aluno diante da necessidade do indivíduo, problematizando as práticas hegemônicas tradicionais.

Como problematizam Passos e Carvalho (2015), a discussão de cuidado na contemporaneidade envolve a necessidade de humanização das práticas em saúde e da integralidade da atenção, na medida em que pedem diálogos e sujeitos, em detrimento de prescrições e objetos (como as doenças, por exemplo).

Considerando que quem demanda atenção (ou o usuário) é um sujeito com expectativas, desejos e história de vida, sendo muito mais do que um corpo adoecido, entendido na 
perspectiva restritamente biológica, o uso da técnica é apenas parte do cuidado. Abrahão e Merhy (2014) abordam a importância de convocar outros meios, incluindo a criatividade, que ajudem a deslocar o foco da doença e ampliem possibilidades de novas práticas construídas a partir da capacidade de combinar diferentes modos de ser, sentir e experimentar, que emergem do encontro entre estudante, docente, usuário e profissional.

Nesse sentido, ao realizarem ações de cuidado, os estudantes também percebem que não é possível apenas aplicar uma técnica e executar o que se aprende previamente, nas aulas, no contexto de vida real encontrado nas atividades práticas do eixo.

Era delicado porque não dava para passar algumas orientações. Porque a pessoa não teria condições para seguir aquela orientação, então, a gente via que o que a gente aprendia na aula não dava para ser muito aplicado no dia a dia. (E2).

Diversos autores problematizam as ações predominantes do nutricionista, baseadas na lógica preventivista, advinda do conhecimento epidemiológico e do conceito de risco, que negligenciam, muitas vezes, algumas dimensões, como os processos de subjetivação inerentes à comida e ao comer, caracterizando uma ação profissional baseada em discursos normativos para mudança de hábitos alimentares, e que visa convencer os sujeitos a aderirem a um projeto dietoterápico (PEDROSO, 2008; BOSI; PRADO, 2011; SANTOS, 2012).

As escolhas alimentares são mediadas por aspectos socioculturais, com hábitos transmitidos de geração a geração, mas que não são imutáveis e sofrem influência da mídia, dos discursos dos profissionais de saúde, do sistema alimentar, que resulta na disponibilidade de gêneros alimentícios, entre outros (CONTRERAS; GRACIA, 2011; VILLAGELIM ET AL., 2012; FREITAS; SANTOS, 2014). Outro aspecto do contexto alimentar contemporâneo é o entendimento de que a alimentação adequada é um dos componentes de um modo de viver saudável, que se define, restritamente, pela dicotomia entre permitido e proibido (CONTRERAS; GRACIA, 2011).

Conhecer esses elementos contribuiria para o alcance de um cuidado nutricional, considerando o sujeito, suas expectativas e seu contexto individual, familiar e comunitário, com vistas a uma abordagem integral e interdisciplinar da alimentação e do cuidado em saúde. As práticas do módulo do eixo favorecem o contato dos estudantes com a vida real e com pessoas que não teriam 'condições para seguir aquela orientação', trazendo à tona a complexidade das orientações nutricionais, contextualizadas e construídas em conjunto com usuários dos serviços e com outros profissionais.

Ainda que a experiência no eixo carregue tensões entre as ações comuns e específicas, os estudantes assinalam um contraponto quando relatam que o aprendizado foi fundamental para uma prática diferenciada nos estágios curriculares. Cabe pontuar que, apesar da formação em comum nos primeiros anos, os estágios são organizados por áreas profissionais e expõem algumas contradições do próprio PPP (Projeto Político Pedagógico). Neste sentido, os alunos se ressentem da ausência do trabalho conjunto com as demais áreas, nesse momento da formação.

Embora o estágio se caracterize como um momento em que a profissão é convocada em sua especificidade, os alunos o reconhecem como uma situação que evidencia o melhor preparo e a possibilidade de sustentação de uma prática decorrente da experiência de trabalho comum e do contato com as pessoas atendidas, no local onde vivem. Há, portanto, uma contaminação do que foi a vivência no eixo:

Eu acho que foi fundamental, esse contato, mesmo porque agora, no campo de estágio, eu estou no estágio de clínica em nutrição, e foi até sugerido usar o tipo de recurso utilizado na TS. Você pega um paciente que está hospitalizado e tenta trabalhar a narrativa da história de vida com esse 
paciente. Nesse sentido, se a gente não tivesse tido essa base, esse contato em TS, esse envolvimento com a população, realizar narrativas de histórias de vida talvez não seria tão enriquecedor agora, no momento do estágio. (E7).

Vale ressaltar que o trecho acima traz o termo 'clínica em nutrição' como referência ao estágio realizado em hospital. Isto coloca, para os docentes, técnicos e estudantes do curso, a necessidade de repensar uma 'clínica' em nutrição que parece ainda remeter à compreensão histórica do surgimento e da atuação do profissional nutricionista (assim como de outros cursos da área da saúde), a partir da divisão técnica do trabalho em saúde.

Para a nutrição, o entendimento da atuação clínica, inclusive como nomenclatura de área específica, perpassa o exercício profissional em ambiente de atenção secundária e terciária em saúde, fruto de sua vertente histórica - e recente, uma vez que a profissão data do início do século XX - e se direciona a ações nas quais o alimento é 'agente de tratamento' (VASCONCELOS; BATISTAFILHO, 2011; DEMETRIO, 2011; VASCONCELOS; CALADO, 2011).

Assim, muitas vezes, a concepção de clínica ainda não consegue superar o enfoque na doença e em procedimentos, face ao cuidado que contextualiza o processo de saúde-adoecimento, produzido em um espaço físico, social, relacional, resgatando as múltiplas dimensões da saúde. Desta forma, a experiência do eixo permite reiterar que repensar a clínica e as concepções de saúde predominantes é um desafio a ser enfrentado na formação do nutricionista.

Além da tensão relacionada às ações comuns e específicas, os estudantes também apontaram alguns desconfortos provenientes da organização do trabalho de campo, especialmente relacionadas à supervisão docente e à continuidade das ações.

Outros estudos apontam para tensões semelhantes em experiências de formação, que integram diversos cursos de graduação na área da saúde e/ou inserem os estudantes nos cenários de práticas (LOBATO ET AL., 2012; AZEVEDO ET AL., 2013; CARVALHO ET AL., 2015).

Quanto aos docentes, os alunos indicam que "os professores novos também precisam ter, fazer TS [...]" (E1), uma vez que os docentes do curso foram formados em instituições com currículos tradicionais.

$\mathrm{Na}$ medida em que não há técnica previamente estabelecida que encaminhe ou facilite os diversos encontros entre alunos de diferentes cursos, entre aluno-docente, aluno-profissional de saúde e aluno-indivíduo/grupo atendido, os docentes são desafiados, convocados a construir, junto a todos os envolvidos, um pensar e agir misturado e combinado, no qual, às vezes, os elementos específicos de sua formação e/ou área de atuação não precisam marcar a diferença entre as ações de cuidado.

Assim, este modelo de formação requer um diálogo permanente com os docentes do eixo específico, sobre as concepções de saúde e cuidado, os possíveis desenhos da supervisão e a condução/discussão das ações propostas ao longo do semestre, o que implica o desafio de formação/discussão entre os professores com vistas a construir uma forma de operacionalização do eixo.

Estar no eixo também demanda um trabalho docente de pactuação, de encontro com outros docentes e de articulações com as questões de saúde pública. Avaliações constantes com docentes, discentes e profissionais necessitam ser realizadas para adequações permanentes. Instigam a discussão da participação/composição de docentes do eixo específico, uma vez que o eixo TS requer a presença dos professores em campo e o refinamento conjunto das estratégias de ensino e concepção dos módulos.

Quanto à continuidade das ações, os estudantes questionam:

[...] passou o tempo de TS, ninguém mais volta lá, acabou. E aquela pessoa, como ficou? (E7). 
A gente vai lá, faz um trabalho super legal, que dura dois meses [...] você realmente vai embora e não sabe se outra pessoa continuou o seu trabalho, se... Que foi válido, você sabe. Mas teve continuidade? (E2).

Para dar conta da continuidade das atividades do eixo, há esforços na articulação das diversas ações da Unifesp-BS, nos diferentes serviços (módulos do eixo, estágios, residência multiprofissional), a partir da fixação do docente em um equipamento/território, bem como da consolidação processual das políticas institucionais de integração ensino-serviço e de educação permanente (Programa de Reorientação da Formação em Saúde, Programa de Ensino pelo Trabalho e Mestrado em Ensino em Ciências da Saúde modalidade profissional, entre outras).

Ao longo dos anos, alguns movimentos foram realizados a partir da experiência, visando ao aprimoramento e à consolidação dessa proposta de formação. São exemplos: a ampliação dos cenários de práticas, incluindo equipamentos de assistência social e educação, hospitais, organizações não governamentais; uma maior articulação com as equipes de saúde, que se dá em diferentes estágios, em cada cenário, para seleção e discussão de condutas e processos.

\section{Considerações finais}

Entre as tensões da experiência em questão, os estudantes apontaram a dificuldade de propostas de cuidado construídas a partir das demandas e significados para o indivíduo/grupo atendido, para além de aspectos técnicos consolidados na área de nutrição, como o diagnóstico nutricional e as orientações dietéticas. Em contrapartida, os alunos reconheceram que a vivência no eixo permite desenvolver o trabalho em equipe e estratégias, como a escuta e o vínculo, que reconhecem o outro como legítimo, com seus saberes e desejos.

Olhar criticamente essa experiência, na perspectiva da formação do nutricionista, permite afirmar que as atividades do eixo Trabalho em Saúde colocam, inevitavelmente, as práticas profissionais em análise, a partir da vivência do trabalho em comum e, à nutrição, faz um convite ao uso de tecnologias compartilhadas e inventivas, afastando-se de uma prática frequentemente normativa e prescritiva, insuficiente para dar conta das questões que envolvem alimentação e nutrição, na atualidade. Trata-se de um 'modo de fazer' a partir de um processo no qual não há receita e se admite criação.

Diante das possibilidades e desafios, dos avanços e tensões da proposta em análise, os estudantes referem abertura para a inovação e para a construção de novas formas de agir profissionalmente no futuro:

A gente tem que estar preparado para tentar, inovar. A gente chegar e tentar demonstrar que existe uma outra proposta de trabalho, que busca escutar, que busca discutir entre todos os profissionais, e a gente inserir isso no mercado de trabalho. Não chegar e já querer encontrar tudo pronto, o que a gente aprendeu, mas construir isso. Acho que o TS permite isso para a gente hoje. (E4).

\section{Colaboradores}

Todas as autoras participaram de todas as etapas do estudo, desde a concepção à aprovação da versão final do manuscrito. 


\section{Referências}

ABRAHÃO, A. L.; MERHY, E. E. Formação em saúde e micropolítica: sobre conceitos-ferramentas na prática de ensinar. Interface (Botucatu), Botucatu, v. 18, n. 49, p. 313-324, jun. 2014.

AROUCA, S. O dilema preventivista. São Paulo: UNESP, Rio de Janeiro: Fiocruz, 2003.

AZEVEDO, B. M. S. A formação médica em debate: perspectivas a partir do encontro entre instituição de ensino e rede pública de saúde. Interface, Botucatu, v. 17, n. 44, p. 187-200, mar. 2013.

BONDIA, J. L. Notas sobre a experiência e o saber da experiência. Revista Brasileira de Educação, Rio de Janeiro, v. 19, p. 20-28, abr. 2002.

BOSI, M. L. M.; PRADO, S. D. Alimentação e nutrição em saúde coletiva: constituição, contornos e estatuto científico. Ciência \&t Saúde Coletiva, Rio de Janeiro, v. 16, n. 1, p. 7-17, jan. 2011.

BRASIL. Ministério da Educação. Resolução CNE/CES $\mathrm{n}^{\circ} 5$, de 07 de novembro de 2001. Institui diretrizes curriculares nacionais do curso de graduação em nutrição. Diário Oficial [da] União, Brasília, DF, 9 nov. 2001. Disponível em: $<$ http://portal.mec.gov.br/cne/arquivos/pdf/CES05.pdf >. Acesso em: 1 mar. 2017.

CAPOZZOLO, A. A. et al. Movimentos de constituição do eixo trabalho em saúde. In: Clínica comum: itinerários de uma formação em saúde. São Paulo: Hucitec, 2013, p. 69-123.

CARVALHO, S. B. O. et al. Parceria ensino e serviço em unidade básica de saúde como cenário de ensino-aprendizagem. Trabalho Educação e Saúde, Rio de Janeiro, v. 13, n. 1, p. 123-144, abr. 2015.

CASETTO, S. J. et al. A investigação da experiência. In: CAPOZZOLO, A. A. et al. Clínica comum: itinerários de uma formação em saúde. São Paulo: Hucitec, 2013. p. 93-102.

CONTRERAS, J.; GRACIA, M. Alimentação, sociedade e distinção social. In: CONTRERAS, J.; GRACIA, M. Alimentação, sociedade e cultura. Rio de Janeiro: Fiocruz, 2011, p. 211-287.

DEMETRIO, F. et al. A nutrição clínica ampliada e a humanização da relação nutricionista-paciente: contribuições para reflexão. Revista de Nutrição, Campinas, v. 24, n. 5, p. 743-763, out. 2011.

FEUERWERKER, L. C. M.; CAPOZZOLO, A. A.

Mudanças na formação dos profissionais de saúde: alguns referenciais de partido do eixo trabalho em saúde. In: CAPOZZOLO, A. A. et al. Clínica comum: itinerários de uma formação em saúde. São Paulo: Hucitec, 2013, p. $35-58$.

FREITAS, M. C. S.; SANTOS, L. A. S. Sobre a fenomenologia do comer saudável no mundo da vida: breve ensaio. In: FREITAS, M. C. S.; SILVA, D. O. Narrativas sobre o comer no mundo da vida. Salvador: Edufba, 2014, p. 33-39.

GATTI, B. A. Grupo focal na pesquisa em ciências sociais e humanas. Brasília, DF: Líber Livro, 2005.

HENZ, A. O. et al. Trabalho entreprofissional: acerca do comum e a cerca do específico. In: CAPOZZOLO, A. A. et al. Clínica comum: itinerários de uma formação em saúde. São Paulo: Hucitec, 2013. p. 163-186.

LOBATO, C. P. et al. A dimensão política na formação dos profissionais de saúde. Physis, Rio de Janeiro, v. 22, n. 4, p. 1273-1291, 2012.

MERHY, E. E. et al. Da repetição à diferença: construindo sentidos com o outro no mundo do cuidado. In: FRANCO, T. B. et al. Afecção e cuidado em saúde. São Paulo: Hucitec, 2010, p. 60-75.

MINAYO, M. C. S. O desafio do conhecimento: pesquisa qualitativa em saúde. 12. ed. São Paulo: Hucitec, 2010.

NUNES, E. D. Interdisciplinaridade: conjugar saberes. Saúde em Debate, Rio de Janeiro. v. 26, n. 62, p. 249-258, set. 2002. 
PASSOS, E.; CARVALHO, Y. M. A formação para o SUS abrindo caminhos para a produção do comum. Saúde e Sociedade, São Paulo, v. 24, supl. 1, p. 92-101, jun. 2015.

PEDROSO, M. B.; CUNHA, M. I. Vivendo a inovação: as experiências no curso de nutrição. Interface (Botucatu), Botucatu, v. 12, n. 24, p. 141-152, mar. 2008.

SANTOS, L. A. S. O fazer educação alimentar e nutricional: algumas contribuições para reflexão. Ciência Et Saúde Coletiva, Rio de Janeiro, v. 17, n. 2, p. 453-462, fev. 2012

SOARES, N. T.; AGUIAR, A. C. Diretrizes curriculares nacionais para os cursos de nutrição: avanços, lacunas, ambiguidades e perspectivas. Revista de Nutrição, Campinas, v. 23, n. 5, p. 895-905, out. 2010.

\section{UNIVERSIDADE FEDERAL DE SÃO PAULO}

(UNIFESP). Projeto político pedagógico: a educação interprofissional na formação em saúde. Santos: Unifesp, 2006. Disponível em: <http://www2.unifesp.br/homebaixada/projetopedagogico_baixada.pdf $>$. Acesso em: 1 mar. 2016.
VASCONCELOS, F. A. G.; BATISTA-FILHO, M. História do campo da Alimentação e Nutrição em Saúde Coletiva no Brasil. Ciência \&t Saúde Coletiva, Rio de Janeiro, v. 16, n. 1, p. 81-90, jan. 2011.

VASCONCELOS, F. A. G.; CALADO, C. L. A. Profissão nutricionista: 70 anos de história no Brasil. Revista de Nutrição, Campinas, v. 24, n. 4, p. 605-617, ago. 2011.

VILLAGELIM, A. S. B. et al. A vida não pode ser feita só de sonhos: reflexões sobre publicidade e alimentação saudável. Ciência \&t Saúde Coletiva, Rio de Janeiro, v. 17, n. 3, p. 681-686, mar. 2012.

YUKA, M. O que sobrou do céu. In: O Rappa. Lado B lado A, 1999

\footnotetext{
Recebido para publicação em outubro de 2016

Versão final em fevereiro de 2017

Conflito de interesses: inexistente

Suporte financeiro: Projeto financiado pelo CNPq - processo n으
} 479031 2008-8 